\title{
MUTYH-Associated Polyposis
}

National Cancer Institute

\section{Source}

National Cancer Institute. MUTYH-Associated Polyposis. NCI Thesaurus. Code C96520.

An autosomal recessive hereditary neoplastic syndrome caused by mutations in the MUTYH gene on chromosome 1p34.1. It is characterized by the presence of multiple colorectal polyps that may progress to carcinoma. Development of gastric and small intestinal polyps may also occur. 